February - 2018

\title{
The Moderating Effects of Group Work on the Relationship Between Motivation and Cognitive Load
}

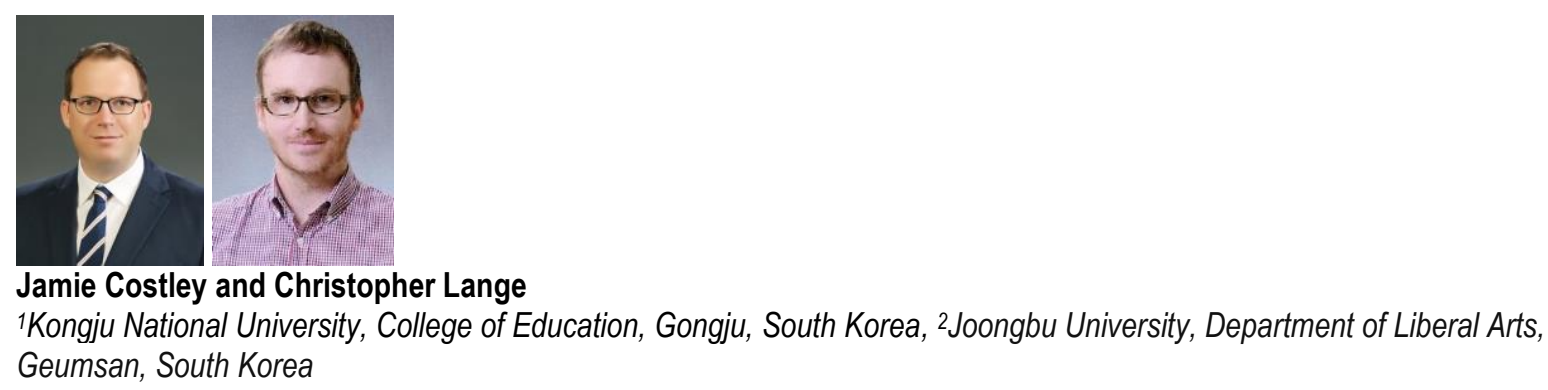

Geumsan, South Korea

\begin{abstract}
Semi-formal learning is used to describe learning that is directed towards the goals of a formal learning institution but outside of the learning structure of a specific class. Students studying online may form semi-formal groups to increase their knowledge of the content by interacting with other learners taking the same class. This study of cyber university students $(n=2042)$ involved looking at the relationship between semi-formal learning groups and levels of germane load. Furthermore, this study sought to understand what role group work plays in moderating the relationship between motivation and germane load. This study found that highly motivated students had higher levels of germane load, and that group work negatively moderated that relationship. In other words, while all students benefited from group work, students with lower levels of motivation benefited more than students with high levels of motivation. This research fills an important gap by showing the value this type of group work can have for all learners, particularly those who may otherwise struggle.
\end{abstract}

Keywords: collaborative learning, germane load, group work, intrinsic motivation, semi-formal learning 


\section{Introduction}

The use of e-learning at universities to optimize resources has been seen as a potential solution in providing high quality education in the face of dropping enrollment and tightening budgets (Lee \& Lee, 2015). Not only institutions, but students themselves, see benefits in taking online classes such as a wider range of courses and flexibility of learning (Parsad, Lewis, \& Tice, 2008) E-learning environments provide great opportunities for potentially high quality learner-to-learner collaborative learning situations. Furthermore, lately there have been increased calls for using group work at universities, emphasizing its value in research concerned with students in tertiary settings (Herrmann, 2013). Also, outside of the pedagogical framework of the university, students are collaborating by generating informal learner-tolearner groups to better understand course content (Vaughan, Nickle, Silovs, \& Zimmer, 2011). Generally speaking, formal learning contexts provide students with specific pedagogical direction and materials, On the other hand, informal learning is learning that is not planned or structured and can happen anywhere (Schugurensky, 2000). While formal group work has been studied in some depth both offline and online (Costley \& Lange, 2016a; Johnson, Johnson, \& Smith, 2014), informal ad-hoc collaborative groups and their effect on learning is an area that has potential for fruitful investigation.

Another term, semi-formal learning, has been used to describe learning that is directed towards the goals of a formal learning institution but outside of the learning structure of a specific class (Jones, Scanlon, \& Clough, 2013). For the purposes of this paper, we will call this "semi-informal." In this context, semiformal learning means students are engaged in learning for the purposes of doing well in a specific class, but outside of the parameters of specific directions from the instructor, for example activities that contribute to the class, but are not part of the formal structure of the lesson (Jones et al., 2013). This type of learning occurs when students need to overcome some of the more challenging situations they may face in e-learning situations (Butson \& Thomson, 2014). Groups engaged in informal learning can be viewed in some way as systems for processing information (Tindale \& Sheffey, 2002). One common justification for this view, and in turn a reason for assigning work to groups, is the limitations of individual students in processing information (Davis, 1980). More specifically, individual members retain information shared in groups better than information learned separately (Tindale \& Sheffey, 2002). While we have learned more about how group collaboration affects processing, group work has limitations in its ability to improve teaching and learning (Kerr, MacCoun, \& Kramer, 1996). For example, certain individuals may retain more information that is shared in the group; however, others may feel overloaded by the interaction (Wittenbaum \& Stasser, 1996).

Extant research has looked into methods of measuring the progress of students who work in groups, and germane cognitive load serves as reliable way to understand and measure the underlying learning processes occurring in both online and offline learning. Germane load is one of three elements that make up cognitive load theory, with the other two being intrinsic and extraneous load. Cognitive load theory relates to an individual's retention of information through processes connected to how learners transfer information from their working memory to their long term memory (Cierniak, Scheiter, \& Gerjets, 2009; Kalyuga, 2011; Sweller, Van Merriënboer, \& Paas, 1998). Because the working memory has a limited capacity for retaining information, instruction that creates excessive processing can create higher levels of 
cognitive load (De Jong, 2010). Levels of information transfer that contribute to learning are either positively or negatively affected depending on the type of information being processed (Chandler \& Sweller, 1991; Mayer \& Moreno, 1998; Mayer \& Moreno, 2003; Moreno, Mayer, Spires \& Lester, 2001). In the case of both intrinsic load (content complexity) and extraneous load (processing of unnecessary information), higher levels are generally considered to not be useful for the learning process, unlike germane load, which directly contributes to learning through student effort to construct schema for the better understanding of information (Sweller et al., 1998). Specifically, when intrinsic load levels are excessive, extraneous load has a negative impact on germane load (van Merriënboer \& Sweller, 2010). Although high levels of both intrinsic load and extraneous load are generally considered detrimental to germane load, there is a balance where a certain amount of intrinsic load may be required for learning to occur. Specifically, high element interactivity that is associated with higher levels of intrinsic load is needed to connect new information to already existing schema and eventually contribute to germane load (Van Merriënboer \& Sweller, 2010). However, if the gap between what a student knows and what a student needs to learn creates excessive cognitive processing when dealing with element interactivity, then learning can be negatively affected (Van Merriënboer \& Sweller, 2010).

The amount of motivation students have towards the class contents affects levels of germane load (Homer, Plass, \& Blake, 2008). As with effort, intrinsic motivation is also important within e-learning (Martens, Gulikerst, \& Bastiaens, 2004). Intrinsic motivation leads to complex processing by learners, as they strive to comprehend more intricate content as an end in itself, rather than for any set of external reasons (Pintrich, 1991). Students that are intrinsically motivated are more likely to form a set of goals that ultimately determine the manner in which they engage the content (Meece, Blumenfeld, \& Hoyle, 1988). Furthermore, intrinsically motivated students are more likely to embrace a mastery orientation, which stems from the belief that knowledge can be shaped through higher levels of effort, and that such effort applied to challenging situations is better for learning (Crippen, Biesinger, Muis, \& Orgill, 2009). One term that focuses on intrinsic reasons for learning as they are related to goal setting is intrinsic goal orientation (IGO). Intrinsic goal orientation refers to the students' internally driven motivation to achieve their general goals of the course (Pintrich, 1991). Students with high levels of intrinsic goal orientation often participate in the learning process out of a sense of challenge, curiosity, or mastery (Pintrich, 1991).The fact that students with low motivation achieve less in some situations, makes group work all the more important, as it may help those that are less motivated increase levels of germane load (Puzziferro, 2008).

\section{Literature Review}

\section{Group Work and Germane Load}

Informal group work can benefit learners by promoting critical thinking, cognitive development, and socialization (Carss, 2007). Further to this, students engaged in varied types of informal learning have shown dramatic increases in higher order cognitive skills in the literature (Collier, 1980). Within informal 
group work, learning is maximized when individual learners contribute towards the common goal of the group through informal interaction (Johnson et al., 2014). Experiments have shown that participating in informal group work aids the learning process, and that the greater the interaction, the greater the learning (Tsay \& Brady, 2010). Group work can be more effective than lecturing in some contexts because students work harder and understand concepts in greater detail (Carlsmith \& Cooper, 2002). These types of learning gains also translate into online group work, as learners who collaborate in online learning communities have shown higher levels of cognition (Akyol \& Garrison, 2008). Such interaction promotes the processes that are involved in the construction of authentic and complex learning (Andriessen, Baker, \& Suthers, 2003), facilitates reflective interaction (Baker \& Lund, 1997) and meaningful communication when dealing with questions (Jonassen \& Kwon, 2001). For example, the self-explanation principle states that when learners are required to explain something to themselves it will optimize their levels of germane load from learning that content (Van Merriënboer \& Sweller, 2010). Further to this point, when learners are required to explain a concept they tend to have a deeper knowledge and understanding of that concept (Williams \& Lombrozo, 2010). Although providing instructional settings that promote this type of learning has is useful to the learning experience, it is not always practical in specific formats of e-learning due to the mass enrollment in university e-learning courses (Yuan \& Powell, 2013). Forming semi-formal learning groups may serve as a substitute for the lack of interaction within massive online courses. Learners who have participated in semi-formal group work have benefited from exploring, engaging in inquiry, and having novel learning experiences (Rogers \& Price, 2008).

While informal group work in some circumstances is beneficial, there are some potential pitfalls or risks. If a learner is part of a group, but does not participate equally with other members, they may not have the opportunity to construct their own knowledge and therefore, learn (Lange, Costley, \& Han, 2016). One example of the problems of unequal participation is "social loafing," where students involved in group work do not contribute, and force the rest of the group to do the majority of the work. Furthermore, when one or more group members are taking a disproportionately greater role, this can crowd out other group members from participating and potentially learning (Kagan, 1989). Interaction by all members has leads to greater understanding by everyone in the group (Zhu, 2012). Furthermore, interaction in an e-learning environment is mostly positive for learners, though the environment must be balanced and consideration must be given to the learner's social and cognitive development (Costley \& Lange, 2016a; Costley \& Lange, 2016b).

Not all situations where learners interact, will lead to cognitive development (Kreijns, Kirschner, \& Jochems, 2003). When more than one learner is interacting with another, there is a cognitive transaction cost caused by the process of sharing the information (Kirschner, Paas, \& Kirschner, 2009). This cost is the time taken to transfer information from one group member to another, and the potential miscommunication that may occur. So while the group has increased its processing power by dividing the workload across working memories interacting together, the transaction cost may offset this balance (Kalyuga, 2011). This can be particularly the case when the task is simple, in that, for more complex tasks, the added mental-power is a net of a benefit, while for simple tasks the transactions costs outweigh the added benefit (Kirschner et al., 2009). Also, when groups work together, the benefits that may be derived 
from the group work in terms of learning and production may take some time to manifest (Gruenfeld \& Hollingshead, 1993). Furthermore, interaction between learners can often lead to off-task social activity, which detracts from the group's ability to process information (Kreijns et al., 2003). While there has been an abundant amount of research that has examined the effects of group work on cognitive processes that lead to learning, the majority of these studies focused on strictly online or strictly offline group work. There is a lack of empirical evidence, however, on the effects of offline group work on germane load among university students enrolled in massive online learning classes.

\section{Intrinsic Goal Orientation and Germane Load}

A meta-analysis study performed by Payne, Youngcourt, and Beaubien (2007) found that research overwhelmingly shows that students who display mastery goal orientation are more successful in terms of learning the content. High levels of IGO are predictors of valuing a deeper understanding of specific tasks and activities (Lyke \& Kelaher Young, 2006). This is reflective of the long-term persistence toward learning that is associated with intrinsic goal orientation (Vansteenkiste, Lens, \& Deci, 2006). The way intrinsically motivated students cognitively process information can help them to gain a better understanding of the content and ultimately increase levels of germane load. Higher levels of germane load can occur when students use available space within their working memory to set goals (Granger, 2012). This is evident in cognitive behavior modification, where setting goals is a part of the modification of one's cognitive processes (Stipek, 1996). Furthermore, the adoption of one's specific goal orientation has an effect on not only their motivation, but also on their cognition and achievement (Wolters, 2004). This is evident in that Pintrich and DeGroot (1990) showed a relationship between intrinsic goal orientation and the use of specific cognitive strategies employed to increase learning. Ultimately, intrinsic goal orientation is specifically believed to be a predictor of students' cognitive processing (Sins, van Joolingen, Savelsbergh, \& van Hout-Wolters, 2008). However, showing a connection between intrinsic goal orientation and cognitive processing falls short in advancing research regarding intrinsic goal orientation and germane load. Further analysis of whether such cognitive processing further leads to more acquisition of knowledge would be useful for the promotion of intrinsic goal orientation.

\section{Group Work, Intrinsic Goal Orientation, and Germane Load}

Rienties, Tempelaar, Van den Bossche, Gijselaers, and Segers (2009) showed that individuals who are intrinsically motivated are more likely to contribute to cognitive task-related discourse through shared information within a group work setting. Additionally, highly intrinsically motivated learners contribute more to planning within a group setting than those that are less intrinsically motivated (Rienties et al., 2009). It is a point of interest to discover whether group work can help less motivated learners learn, or conversely, whether highly motivated learners may struggle within their coexistence with others with differing goals. Addressing the latter issue, Järvelä, Volet, and Järvenoja (2010) claimed that although motivation is an important part of collaboration, it comes with some challenges within a group setting. Each member of a small group brings with them a different set of goals, cognitions, and set of motivational beliefs, which can create conflict within a group setting as members struggle to find a common ground (Järvelä et al., 2010). 
When entering a group work setting, an individual's set of goals needs to give way to group goals (Wosnitza \& Volet, 2009). While this may be challenging for high intrinsically goal oriented students, it can pave the way for lower motivated students to succeed within a group work setting. Reflective of this, Pee, Kankanhalli, and Kim (2010) claimed that once interdependent goals are successfully set within a group setting, knowledge sharing intrinsically follows, allowing all learners to receive support from group members. This effectively allows lower motivated students to become part of the knowledge sharing process. Intrinsically motivated learners can assure that this occurs by striving for positive interdependence, which exists when group members come to the understanding that they can succeed only if all members achieve the shared goals of the group (Johnson \& Johnson, 2003). When high intrinsically motivated students realize their success as a group is based on the work of others, they are more likely to share information (Nichols \& Miller, 1994). Accordingly, lower motivated students effectively become the beneficiaries of the effort put forth by the high intrinsic students. Furthermore, it may be the case that low motivated students will be more likely to adopt a set of goals to help them learn within a group setting (Johnson \& Johnson, 2003). Existing research provides some insight into the processes that are occurring within group work, as students with varying levels of motivation interact with each other in ways that can impact their acquisition of knowledge. It would be of particular use for elearning research to examine these effects within offline groups that are formed to gain a better understand of instruction within online settings.

\section{The Current Study}

This research examined students participating in classes at the Open Cyber University (OCU) in South Korea, which provides online credit classes for students who are enrolled at one of the 23 traditional brick-and-mortar universities that make up the OCU consortium. The OCU is currently the largest cyber university in South Korea with approximately 120,000 students participating in about 400 classes (Open Cyber University of Korea, n.d.). Students working together in groups as part of their class improve cognitive strategies and processes that contribute to learning (Johnson et al., 2014; Korkmaz, 2012). With this in mind, it is important to understand if the benefits of group work can be transferred to gains in cognitive load as well (Van Merriënboer, \& Sweller, 2010). Specifically, this study looks at the moderating effect of informal offline group work on the relationship between intrinsic goal orientation and germane

load. This study hypothesizes that the moderating effect of group work reduces the relationship between intrinsic goal orientation and germane load. With this in mind, this study explores the research question: Does group work benefit the learning of students with lower levels of motivation more than it benefits students with higher levels of motivation. Therefore, the current study examines the following hypotheses:

H1. Group work is positively correlated with germane load.

H2. Motivation is positively correlated with germane load.

H3. Motivation is positively correlated with group work.

H4. Group work moderates the relationship between intrinsic goal orientation and germane load. 


\section{Methods}

\section{Research Procedures and Data Collection}

The first step in this study was a development of a survey that focused on learners' self-directed behavior such as offline group work. The initial survey was translated from English into Korean. An expert in the OCU and e-learning checked the translations and found them to be rigorous and correct representations of the English items. The items were then uploaded into a Google Sheets form and a link to the form was created. This link was sent to the OCU's administration who reviewed its acceptability for their students. Once the survey was accepted, a link was put on the main information board on the OCU, and students were invited to fill out the survey (see Appendix).

\section{Participants}

Participants of this study attended OCU classes in the Spring semester of 2016, and filled out the survey in June 2016 at the end of the Spring semester. Two thousand six hundred eighty-nine students of the 120,000 studying in the OCU submitted surveys. From the 2689 surveys submitted, 613 failed to respond to parts of the survey that were pertinent to this research. Those surveys were removed from analysis, leaving 2076 valid responses. The next step in this research was the removal of outliers. Linear regression of group work levels and intrinsic goal orientation onto germane load was used to generate Mahalanobis, Cook's, and Leverage values to look for outliers. Any participants whose results met the standard for two or more of these tests was removed from the analysis leaving 2042. There were no shared traits among the discarded participants, except for them not filling out the survey completely or being outliers in relation to this research. All following results and tables subsequent to this are generated from these 2042 valid subjects. Of the 2042, 1061 (52\%) were female and 981 (48\%) were male. The average age of the subjects that were a part of this study was 23.7 , with a standard deviation of 3.4. The oldest subject was 63 , and the youngest was 19. Other studies of the OCU have found a similar distribution of gender and age (Suh \& Kim, 2013). The respondents took a wide variety of classes in the OCU. Students in the OCU have been shown to take a similar distribution of courses: liberal arts (33\%), social science (17\%), technology (15\%), lifestyle and health (12\%), management and business (8\%), foreign language (7\%), natural science (6\%), and design (2\%) (Kobayashi \& Kim, 2010).

\section{Instruments}

\section{Group Work}

To generate the indicators for measuring the varying types of group work, 10 OCU students were asked to describe types of out of class small group work the students engaged in motivated by their OCU class. The list created by the authors was then discussed with the students (6) who had engaged in this type of group work, and the students agreed that the list seemed to accurately represent the differing possible or likely 
types of group work. This method of item development follows the procedure set out in Costley and Lange (2017). To understand the types of group work, students were asked to respond to one single item. The item related to the variety of types of group work student engaged in and asked students:

- How did you interact with people you know offline who were taking the same class? (Please check all that apply).

Below this, the students could check boxes with the options:

- We talked generally about the class ("The class is easy, the class is stressful"); we talked about the contents of the class, we studied together, we shared notes or materials, other, I never interacted with anyone offline, we cheated on exams or quizzes.

The responses were then coded into seven separate variables as either occurring or not-occurring, and the five positive indicators (excluding "I never interacted with anyone offline" and "we cheated on exams or quizzes") were combined by addition into a single additive index: group work. It is that index that is used in this research to measure the variety of group work students were engaged in. The types of activities that were covered under the other category included but was not limited to: editing others work, checking answers, and reminders about dates/times/assessment.

\section{Germane Load}

The germane load measurement used in this study was made up of four items from Leppink, Paas, Van der Vleuten, Van Gog, and Van Merriënboer's (2013) paper titled "The development of an instrument for measuring cognitive load." The Likert-type scale used for these items was set at a range from 1 to 7 , with 1 representing "strongly disagree" and 7 representing "strongly agree". This current research uses the four items measuring germane load: 1) The lecture really enhanced my understanding of the topic, 2) the lecture really enhanced my knowledge and understanding of the of the class subject, 3) the lecture really enhanced my understanding of the concepts associated with the class subject, and 4) the lecture really enhanced my understanding of concepts and definitions. These items contain a limited modification of Leppink et al.'s (2013) research in that the word "lecture" replaces the word "activity" to focus in on the main instructional aspect of the OCU which are the lectures. This was done in accordance to Leppink et al.'s (2013) claim that rewording text to match the context of a specific study is an acceptable modification to the items and has also justified by numerous other studies (Costley \& Lange, 2017; Debue \& Van De Leemput, 2014; Kozan, 2015; Leppink, Paas, Van Gog, van Der Vleuten, \& Merrienboer, 2014; Morrison, Dorn, \& Guzdial, 2014). Although the Leppink et al.'s (2013) cognitive load scale was originally designed to be set at a $o$ to 10 Likert-type scale, the current study set it at 1 to 7 to ensure consistency with the range throughout the entire survey. This was done because the main construct used in this study is the intrinsic goal orientation construct, which is set at a 1 to 7 range. Justification for altering the range is provided by Debue and Van De Leemput (2014). Cronbach's alpha for the germane load construct was calculated to be .918, which is high enough for research of the type being conducted. 
In Leppin et al.'s (2013) research, exploratory factor analysis was used to understand how parts of cognitive load relate to each other. The fact that the loadings for intrinsic load, extraneous load, and germane load independently represented a robust factor supports the triarchic theory of cognitive load, which according to Deleeuw and Mayer (2008) allows for different aspects of cognitive load to be measured separately. However, a 2014 study by Leppink, Paas, Van Gog, Der Vleuten, and Van Merrienboer (2014) indicated that germane load may be more of representation of intrinsic load, rather than invested effort that contributes to learning, which is how past research has conventionalized it. However, this point is refuted by a more recent study conducted by Debue and van de Leemput (2014), who, using Leppink et al.'s (2013) cognitive load items, performed analysis to determine what their germane load items actually represent. However, their results differed from Leppink et al. (2013) in that the germane load items were found not to be related to intrinsic load, but a true representative of germane load and how it has been conceptualized by past research. The latter study is used as justification for the germane load items used in the current study.

\section{Intrinsic Goal Orientation}

The measurements used to calculate intrinsic goal orientation came from the Motivated Strategies for Learning Questionnaire (MSLQ), which is used to assess college students' motivational orientations and their use of different learning strategies (Pintrich, 1991). The Likert-type scale used for these items was set at a range from 1 to 7 , with 1 representing "strongly disagree" and 7 representing "strongly agree." The MSLQ contains a variety of constructs measuring students' levels of motivation and learning strategies. From the MSLQ, the following four items were adapted for use in this study to intrinsic goal orientation: 1) In a class like this, I prefer course material that really challenges me so I can learn new things; 2) In a class like this, I prefer course material that arouses my curiosity, even if it is difficult to learn; 3) The most satisfying thing for me in this course is trying to understand the content as thoroughly as possible; and 4) When I have the opportunity in this class, I choose course assignments that I can learn from even if they don't guarantee a good grade. The Cronbach's alpha was much higher at .833, which is acceptable for this type of research.

\section{Results}

Out of 2042 students who were involved in this research 987 (48\%) had no offline contact with other OCU students regarding the classes, while 1055 (52\%) did have some type of offline interaction. To understand the main hypotheses of this research, Pearson's bivariate correlations were calculated. As can be seen in Table 1, there was a statistically significant positive relationship between offline interaction and germane load of .444. This shows that as offline interaction increases, so does the student's levels of germane load. Furthermore, intrinsic goal orientation was statistically significantly correlated positively with germane load (.401). This shows that students with higher levels of intrinsic goal orientation will have higher levels of germane load. Also, intrinsic goal orientation was statistically significantly positively correlated with group work (.147), meaning that students with higher levels of intrinsic goal orientation were more likely to interact with other students offline. 
Table 1

Descriptive Statistics and Correlations Between the Main Variables $(n=2042)$

\begin{tabular}{|l|l|l|l|l|l|}
\hline & Mean & Range & 1 & 2 & 3 \\
\hline Group work & N/A & $0-5$ & 1 & & \\
\hline Intrinsic goal orientation & 3.94 & $1-7$ & $.147^{* *}$ & 1 & \\
\hline Germane load & 4.38 & $1-7$ & $.444^{* *}$ & $.401^{* *}$ & 1 \\
\hline
\end{tabular}

${ }^{*} p=<0.05$

To gain a deeper understanding of the relationship between offline student to student interaction and germane load, the individual indicators that make up the offline interaction index were calculated and can be seen in Table 2. This table shows the total amount of types of group work survey participants were involved in as either "occurring" meaning the participant engaged in that activity, or "not occurring" meaning the participant did not engage in that activity. Of the individual indicators the most common was to talk generally about the class (496), then talk about the contents (419), third sharing notes (310), then other (392), and finally studying together (298). All indicators had a statistically significant positive relationship with germane load. The indicator with the strongest relationship with germane load was studying together (.397), second sharing notes (.291), then talking about contents (.275), fourth other (.266), and lastly talking generally about the class (.204).

Table 2

The Occurrence of the Indicators and Their Correlations With Germane Load ( $n=2042)$

\begin{tabular}{|l|l|l|l|}
\hline & Not occurring & Occurring & Correlation with germane load \\
\hline Talk generally & 1546 & 496 & $.204^{* *}$ \\
\hline Talk about contents & 1623 & 419 & $.275^{* *}$ \\
\hline Shared notes & 1650 & 392 & $.291^{* *}$ \\
\hline
\end{tabular}




\begin{tabular}{|l|l|l|l|}
\hline Other & 1741 & 301 & $.266^{* *}$ \\
\hline Study together & 1744 & 298 & $.397^{* *}$ \\
\hline
\end{tabular}

** $p=<0.01$

Using linear regression both group work and intrinsic goal orientation's relationship with on germane load was measured (Table 3). The overall model had strong predictive power in relation to germane load $\left(R^{2}=.32\right)$. Also, each one unit increase in the group work scale lead to a moderate $41(p=<.001)$ increase in germane load. Also, for every one unit increase in intrinsic goal orientation there was a moderate .35 (p $=<.001$ ) increase in germane load. As age had a statistically significant relationship with intrinsic goal orientation and germane load, and gender had a statistically significant relationship with intrinsic goal orientation they were added as covariates to the model. However, the addition of age and gender to the model made an insignificant impact on the model ( $R^{2}$ changed from .3166 to .3174$)$ that the results show in this study do not contain age or gender as covariates.

Table 3

Standard Multiple Linear Regression of Offline Interaction and Intrinsic Goal Orientation on Germane Load

\begin{tabular}{|l|l|l|l|l|l|l|l|l|}
\hline & B & SE & $\beta$ & $R$ & $R^{2}$ & F & Sig & $\begin{array}{l}\text { Semi- } \\
\text { partial }\end{array}$ \\
\hline Model 1 & & & & .559 & .322 & 462.8 & .000 & \\
\hline $\begin{array}{l}\text { Group } \\
\text { work }\end{array}$ & .413 & .019 & .408 & & & & .000 & .399 \\
\hline IGO & .346 & .018 & .348 & & & & .000 & .342 \\
\hline
\end{tabular}

To further establish the relationship between the main variables, ANOVA was also used. Group work variable was split into two groups, subjects who had either engaged in some type of group work, or those who had engaged in no group work. The intrinsic goal orientation was also split into two groups with those at or below the average being the "low" group, and those above the average being the "high" group. While there is a loss of information when linear variables are put into groups, or the amount of nominal groups are reduced, in this research the basic relationships between the variables are maintained, though they are not as strong as the relationships established using regression. The ANOVA results showed a total $R^{2}$ value of .15 (adjusted $R^{2} .15$ ). 


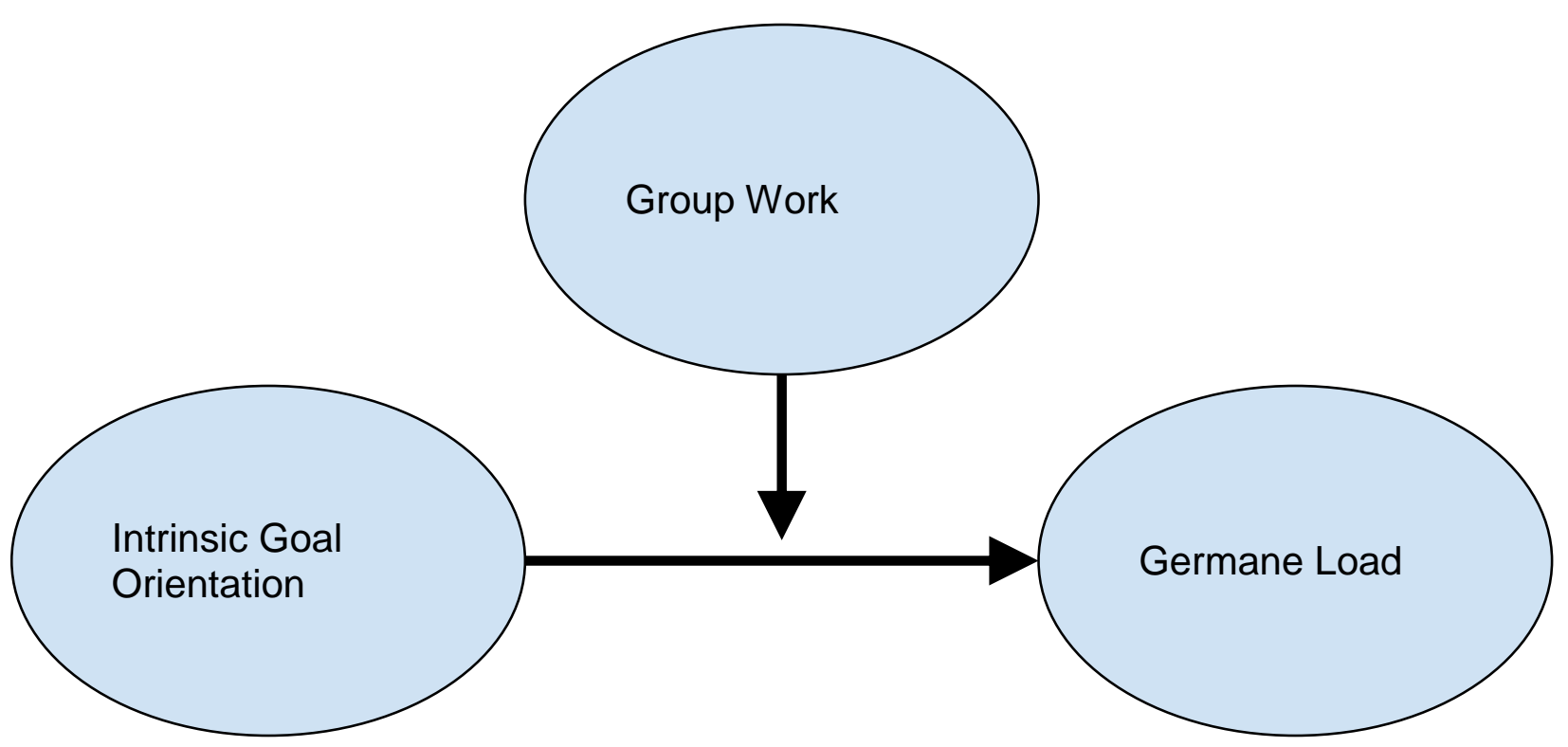

Figure 1. The moderating effects of group work on the relationship between intrinsic goal orientation and germane load.

PROCESS macro (model 1, Hayes, 2013) was used to test the interaction effect of group work levels and intrinsic goal orientation on germane load as is shown in Figure 1. To show this, 10,000 bootstrap samples with a 95\% confidence interval were used. Also, variables were mean centered to +/- 1 standard deviation, to reduce multi-collinearity. The results showed strong evidence of an interaction effect based on a standardized coefficient. Group work negatively moderated the effect of intrinsic goal orientation on germane load, or in other words, as levels of group work increase, the strength of relationship between intrinsic goal orientation and germane load decreases.

Table 4

Centered Effects for Intrinsic Goal Orientation on Germane Load at Each Level of Group Work

\begin{tabular}{|l|l|l|l|l|}
\hline & Group work & $b$ & $t$ & $p$ \\
\hline Low group work & -.9334 & .3932 & 16.7971 & .000 \\
\hline Average group work & .0000 & .3478 & 18.8261 & .000 \\
\hline High group work & .9334 & .2878 & 12.2435 & .000 \\
\hline
\end{tabular}

To measure the effect of moderation, PROCESS macro was used to center the variables and measure the relative effect of intrinsic goal orientation on germane load at the-average level of group work, and at one standard deviation above and below the mean. This created a low, average, and high grouping of relationships. In all conditions, there was a statistically significant relationship between intrinsic goal 
orientation and germane load. However, as can be seen in Table 4, in the low group work condition the effect size (.39) is stronger than in the average group work condition (.35) and much stronger than in the high group work condition (.28). As can be seen in Figure 2, this creates an effect, whereby the low group work condition has a steeper line than the average group work condition and the high group work condition. In this case, the lines representing the three levels get closer together as group work increases. This shows that group work weakens the relationship between intrinsic goal orientation and germane load.

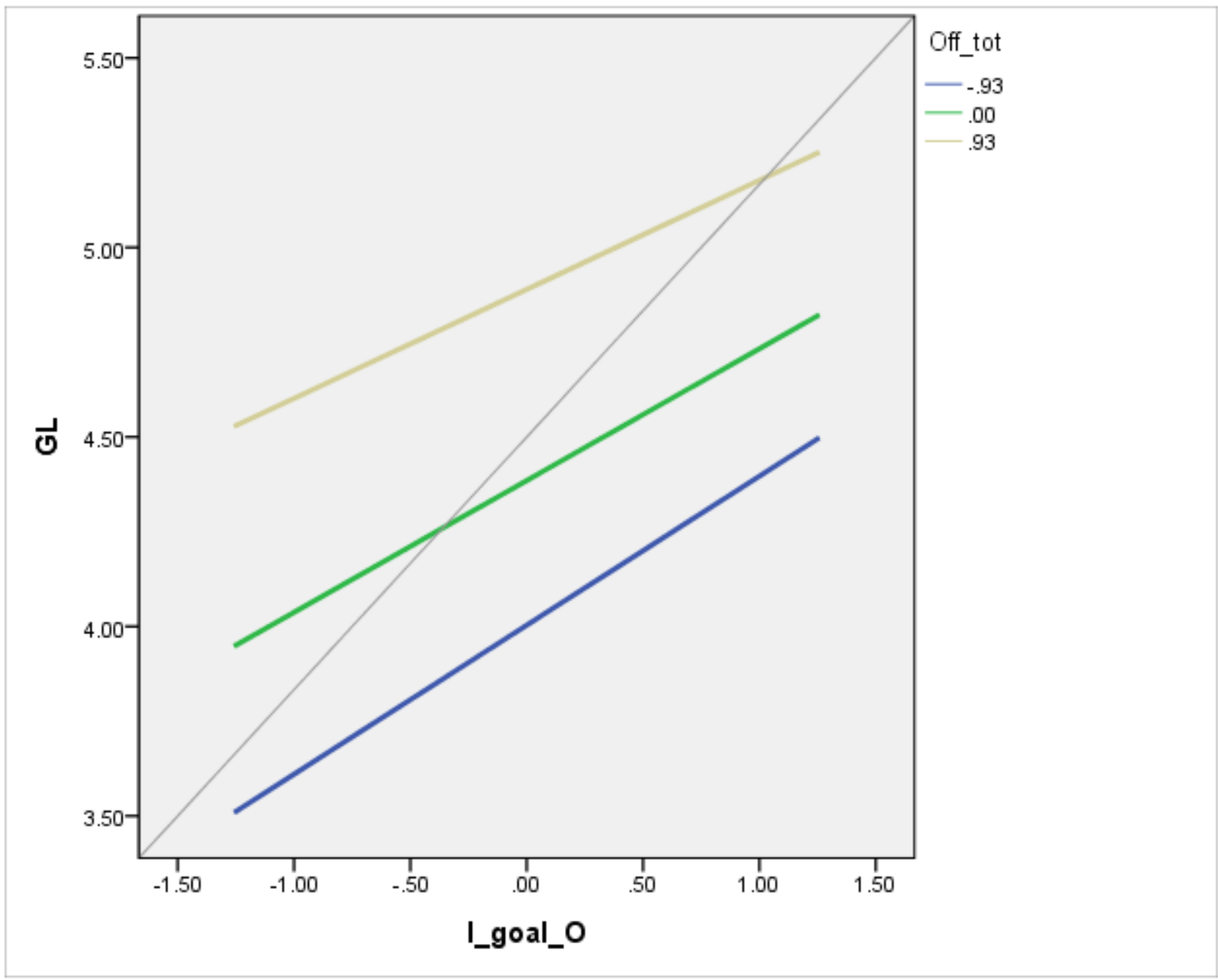

Figure 2. The relationships between intrinsic goal orientation and germane load by group work level.

\section{Discussion}

More than half of the students (52\%) that were a part of this study were engaged in some level of offline informal group work. Research has shown that universities are good environments for informal group work, and that students should have the ability to be a productive part of a learning group (Herrmann, 2013; Johnson et al., 2014). The levels of informal group work that have been found in this study are 
unsurprising, in view of the fact that many students find learning complex information in an online class difficult (Butson \& Thomson, 2014). While group work make have some downsides and students do not always enjoy or feel like they benefit from group work (Kagan, 1989; Onwuegbuzie, Collins, \& Jiao, 2009); Zhu, 2012), a little over half the students in this study decided to do group work. There is some research that suggests that group work may not lead to gains in germane load (Kreijns et al., 2003). This may be because of transaction costs, lag in the cognitive benefits of interacting within a group, or off-task behavior (Gruenfeld, \& Hollingshead, 1993; Kerr et al., 1996; Kirschner et al., 2009; Kreijns et al., 2003; Wittenbaum \& Stasser, 1996). The results of the present study go some way to contradicting this point of view, and suggests that offline informal group work does benefit learner's levels' of germane cognitive load. Specifically, the contention that off-task social behavior may negatively affect learning is directly contradicted by this study, which showed that social interaction by learners (discussing their feelings about the classes) correlated with higher levels of germane cognitive load. This current research supports the notion that higher order cognitive skills, in the form of germane cognitive load, can be improved by semi-formal group work (Collier, 1980). A possible reason for the cognitive benefits found in the current study is that the novelty and interest generated by this type of the learning experience leads to a great deal of learning (Rogers \& Price, 2008). Furthermore, the cognitive gains found from group work in this study may also be attributed to the variety of processes often inherent in group work. For example, tasks can become more engaging and complex (Andriessen et al., 2003), the interaction can promote reflection (Baker \& Lund, 1997), and more meaningful engagement with the contents of the class (Jonassen \& Kwon, 2001).

Some research claims that engaging, helping, and being helped by others increases motivation (Järvelä et al., 2010; Johnson \& Johnson, 2003). Or, conversely, some have claimed that students who are intrinsically goal oriented may be more likely to contribute to task-related discourse and planning when engaging in group work (Rienties et al., 2009). This provides some lack of clarity in how the relationship between the OCU students' levels of intrinsic goal orientation and group work co-occur. This study showed that there was a statistically significant correlation between intrinsic goal orientation and germane cognitive load (.401). As with the current study, some research has shown that students with high levels of motivation and effort are likely to learn more, and students with low levels of motivation and effort are likely to learn less (Homer et al., 2008; Martens et al. 2004). In the case of this research, students with low motivation may have felt less engaged with the contents and therefore less likely to get cognitive gains from the class contents. Students who were a part of this study who had high levels of intrinsic goal orientation likely valued deeper understanding of the topics, and tried to master the contents regardless of extrinsic motivating factors (Lyke \& Kelaher Young, 2006; Vansteenkiste et al., 2006).

This research looked at how group work and intrinsic goal orientation interact to affect germane cognitive load. It was shown that as group work increased, the relationship between IGO and germane load decreased. Although IGO was generally found to have a positive relationship with germane load, the relationship was shown to be weaker in the high group work condition, showing that there is less of a benefit to having high levels of IGO than it is to have low levels of IGO when group work is involved. This 
is not to say that high intrinsic motivation is detrimental to group work, but rather that low intrinsically motivated students stand to benefit more from group work than high intrinsically motivated students. Additionally, there may be more issues that high intrinsically motivated students encounter when collaborating with other students who have their own set of intrinsic goals. Reflective of this notion, Järvelä et al. (2010) have stated that because highly motivated students enter group work with stronger pre-formed beliefs, cognitions, and goals, a greater chance of conflict may present more of a challenge for high intrinsically motivated students than it would have for low intrinsically motivated students. Because less intrinsically goal oriented students are less likely to enter group work with pre-formed ideas that may clash with those of other group members, they may be able to better focus their cognitive processing to acquire knowledge, rather than trying to resolve conflict. Although high intrinsic goal oriented students coalescing together may struggle to find mutual agreement on the setting of goals and ways in which to accomplish those goals, they are still more likely to be at the forefront of the knowledge sharing process, effectively allowing all learners, including low motivated students, to process shared information (Nichols \& Miller, 1994; Pee et al., 2010; Rienties et al., 2009), which may help lower motivated students more effectively process information. Furthermore, the low motivated students may be more likely to form a set of goals within a group work setting than if they work alone (Johnson \& Johnson, 2003), allowing them to better take advantage of the group work setting.

\section{Conclusion and Limitations}

When specific interactive elements are not included within e-learning environments due to the impracticality resulting from massive enrollment, it is beneficial for students to participate in semi-formal group work that can help them process shared information in a way that is helpful to learning. The results of this study highlight the importance of such group work for those students who are less intrinsically motivated, as they tend to benefit more from collaborating with other students who are taking the same class. Based on the results of this study, in settings where online interaction may be limited, semi-formal group work should be encouraged as a means of enhancing the learning experience, specifically to those who may be less intrinsically motivated. Encouraging such group work may allow low intrinsically motivated students to enhance their cognitive processing in a way that ultimately contributes to their understanding of the e-learning content. The practical significance of the currents study is that unlike previous research, semiformal learning among online learners is promoted as a means to promote learning among low motivated students who are the main beneficiaries of the knowledge sharing process. There are, however, limitations to this study. Unfortunately, the complexity of the tasks undertaken by the OCU students is unknown. Therefore, it is unknown whether the complexity of the tasks played a role in how much or how little the students benefited from group work. Examining this would provide more insight into the results of the current study. Additionally, taking a qualitative approach to this study may provide clearer picture into how students specifically processed information within the semi-formal groups, and whether such strategies ultimately contributed to the learning process. 


\section{References}

Akyol, Z., \& Garrison, D. R. (2008). The development of a community of inquiry over time in an online course: Understanding the progression and integration of social, cognitive and teaching presence. Journal of Asynchronous Learning Networks, 12(2-3), 3-23.

Andriessen, J., Baker, M., \& Suthers, D. (2003). Arguing to learn. Confronting cognitions in computersupported collaborative learning environments. Dordrecht: Kluwer

Baker, M., \& Lund, K. (1997). Promoting reflective interactions in a CSCL environment. Journal of Computer Assisted Learning, 13(3), 175-193.

Butson, R., \& Thomson, C. (2014). Challenges of effective collaboration in a virtual learning environment among undergraduate students. Creative Education, 5, 1449-1459.

Carlsmith, K. M., \& Cooper, J. (2002). A persuasive example of collaborative learning. Teaching of Psychology, 29, 132-135

Carss, W.D. (2007). The effects of using think-pair-share during guided reading lessons (Doctoral dissertation, The University of Waikato, Diterbitkan) Retrieved from https://researchcommons.waikato.ac.nz/handle/10289/2233

Chandler, P., \& Sweller J. (1991). Cognitive load theory and the format of instruction. Cognition and Instruction, 8(4), 293-332.

Cierniak, G., Scheiter, K., \& Gerjets, P. (2009). Explaining the split-attention effect: Is the reduction of extraneous cognitive load accompanied by an increase in germane cognitive load? Computers in Human Behavior, 25, 315-324.

Collier, K. G. (1980). Peer-group learning in higher education: The development of higher order skills. Studies in Higher Education, 5(1), 55-62.

Costley, J., \& Lange, C. (2016a). The relationship between social presence and critical thinking: Results from learner discourse on an asynchronous learning environment. The Journal of IT Education: Research, (15), 89 - 108.

Costley, J., \& Lange, C. (2016b). The effects of instructor control of online learning environments on satisfaction and perceived learning. The Electronic Journal of e-Learning 14(3), 169- 170. 
Costley, J. \& Lange, C. (2017). The effects of lecture diversity on germane load. The International Review of Research in Open and Distributed Learning 18(2). doi: http://dx.doi.org/10.19173/irrodl.v18i2.2860.

Crippen, K. J., Biesinger, K. D., Muis, K. R., \& Orgill, M. (2009). The role of goal orientation and selfefficacy in learning from web-based worked examples. Journal of Interactive Learning Research, $20(4), 385$.

Davis, J. H. (1980). Group decision and procedural justice. In M. Fishbein (Ed.), Progress in social psychology (Vol. 1, pp. 157-230). Hillsdale, NJ: Erlbaum.

Debue, N., \& Van De Leemput, C. (2014). What does germane load mean? An empirical contribution to the cognitive load theory. Frontiers in Psychology, 5 .

DeLeeuw, K. E., \& Mayer, R. E. (2008). A comparison of three measures of cognitive load: Evidence for separable measures of intrinsic, extraneous, and germane load. Journal of Educational Psychology, 100(1), 223.

De Jong, T. (2010). Cognitive load theory, educational research, and instructional design: Some food for thought. Instructional Science, 38(2), 105-134.

Granger, B. P. (2012). Enhancing training outcomes in the context of e-learning: The impact of objective learner control, training content complexity, cognitive load, learning goal orientation, and metacognitive strategies (Doctoral dissertation, University of South Florida, Florida). Retrieved from http://scholarcommons.usf.edu/etd/4326/

Gruenfeld, D. H., \& Hollingshead, A. B. (1993). Sociocognition in work groups the evolution of group integrative complexity and its relation to task performance. Small Group Research, 24(3), 383405 .

Hayes, A. F. (2013). Introduction to mediation, moderation, and conditional process analysis. New York: The Guilford Press

Herrmann, K. J. (2013). The impact of cooperative learning on student engagement: Results from an intervention. Active Learning in Higher Education, 14(3), 175-187.

Homer, B. D., Plass, J. L., \& Blake, L. (2008). The effects of video on cognitive load and social presence in multimedia-learning. Computers in Human Behavior, 24(3), 786-797.

Järvelä, S., Volet, S., \& Järvenoja, H. (2010). Research on motivation in collaborative learning: Moving beyond the cognitive-situative divide and combining individual and social processes. Educational Psychologist, 45(1), 15-27. 
Johnson, D. W., \& Johnson, R. T. (2003). Student motivation in cooperative groups: Social independence theory. In R. M. Gillies \& A. F. Ashman (Eds.), Co-operative learning: The social and intellectual outcomes of learning in groups (pp. 36-176), London, UK: Routledge.

Johnson, D. W., Johnson, R. T., \& Smith, K. A. (2014). Cooperative learning: Improving university instruction by basing practice on validated theory. Journal on Excellence in University Teaching, 25(4).

Jonassen, D. H., \& Kwon, H. I. (2001). Communication patterns in computer mediated and face-to-face group problem solving. Educational Technology Research and Development, 49(1), 35-51.

Jones, A. C., Scanlon, E., \& Clough, G. (2013). Mobile learning: Two case studies of supporting inquiry learning in informal and semiformal settings. Computers and Education, 61(1), 21-32.

Kagan, S. (1989). The structural approach to cooperative learning. Educational Leadership, 47(4), $12-15$.

Kalyuga, S. (2011). Cognitive load theory: How many types of load does it really need? Educational Psychology Review, 23(1), 1-19.

Kerr, N. L., MacCoun, R. J., \& Kramer, G. P. (1996). Bias in judgment: Comparing individuals and groups. Psychological Review, 103, 687-719.

Kirschner, F., Paas, F., \& Kirschner, P. A. (2009). A cognitive load approach to collaborative learning: United brains for complex tasks. Educational Psychology Review, 21, 31-42.

Kobayashi, T., \& Kim, Y. (2010). The status of cyber education in Korean higher learning: The potential for East Asian linkage in higher education. The Open University of Japan Repository. Retrieved from https://ouj.repo.nii.ac.jp

Korkmaz, Ö. (2012). A validity and reliability study of the online cooperative learning attitude scale (OCLAS). Computers \& Education, 59(4), 1162-1169.

Kozan, K. (2015). The predictive power of the presences on cognitive load. (Doctoral dissertation, Purdue University). Retrieved from https://docs.lib.purdue.edu/open_access_dissertations/491/

Kreijns, K., Kirschner, P. A., \& Jochems, W. (2003). Identifying the pitfalls for social interaction in computer-supported collaborative learning environments. A review of the research. Computers in Human Behavior, 19(3), 335-353

Lange, C., Costley J., \& Han, S. (2016). Informal cooperative learning in small groups: The effect of scaffolding on participation. Issues in Educational Research, 26(2), 260 - 279.

Lee, H. \& Lee, S. (2015). Analysis of various influences and factors on academic persistence of cyber 
university students. International Journal of Service, Science and Technology 8(10), pp 211-222.

Leppink, J., Paas, F., Van der Vleuten, C. P., Van Gog, T., \& Van Merriënboer, J. J. (2013). Development of an instrument for measuring different types of cognitive load. Behavior research methods, 45(4), 1058-1072.

Leppink, J., Paas, F., Van Gog, T., van Der Vleuten, C. P., \& Van Merrienboer, J. J. (2014). Effects of pairs of problems and examples on task performance and different types of cognitive load. Learning and Instruction, 3o, 32-42.

Lyke, J. A., \& Kelaher Young, A. J. (2006). Cognition in context: Students' perceptions of classroom goal structures and reported cognitive strategy use in the college classroom. Research in Higher Education, 47(4), 477-490.

Martens, R. L., Gulikerst, J., \& Bastiaens, T. (2004). The impact of intrinsic motivation on e-learning in authentic computer tasks. Journal of Computer Assisted Learning, 2o(5), 368-376.

Mayer, R. E., \& Moreno, R. (1998). A split-attention effect in multimedia learning: Evidence for dual processing systems in working memory. Journal of Educational Psychology, 9o(2), 312-320. http://doi.org/10.1037//0022-0663.90.2.312

Mayer, R. E., \& Moreno, R. (2003). Nine ways to reduce cognitive load in multimedia learning. Educational Psychologist, 38(1), 43-52.

Meece, J. L., Blumenfeld, P. C., \& Hoyle, R. H. (1988). Students' goal orientations and cognitive engagement in classroom activities. Journal of Educational Psychology, 8o(4), 514.

Moreno, R., Mayer, R. E., Spires, H. A., \& Lester, J. C. (2001). The case for social agency in computerbased teaching: Do students learn more deeply when they interact with animated pedagogical agents? Cognition and instruction, 19(2), 177-213.

Morrison, B. B., Dorn, B., \& Guzdial, M. (2014, July). Measuring cognitive load in introductory CS: adaptation of an instrument. In Proceedings of the tenth annual conference on international computing education research (pp. 131-138). ACM.

National Center for Education Statistics. (2008). Distance education at degree-granting postsecondary institutions: 2006-07. US Department of Education. NCES 2009-044.

Nichols, J. D., \& Miller, R. B. (1994). Cooperative learning and student motivation. Contemporary Educational Psychology, 19(2), 167-178.

Onwuegbuzie, A. J., Collins, K. M., \& Jiao, Q. G. (2009). Performance of cooperative learning groups in a postgraduate education research methodology course: The role of social interdependence. Active 
Learning in Higher Education, 10(3), 265-277.

Open Cyber University of Korea. (n.d.). Why OCU? [Blog post]. Retrieved from http://www.ocu.ac.kr/foreign/english/About_ocu/subo5.asp

Parsad, B., Lewis, L., \& Tice, P. (2008). Distance education at degree-granting postsecondary institutions: 2006-2007. Washington, DC: National Center for Education Statistics, Institute of Education Sciences, US Department of Education.

Payne, S. C., Youngcourt, S. S., \& Beaubien, J. M. (2007). A meta-analytic examination of the goal orientation nomological net. Journal of Applied Psychology, 92(1), 128.

Pee, L. G., Kankanhalli, A., \& Kim, H. W. (2010). Knowledge sharing in information systems development: A social interdependence perspective. Journal of the Association for Information Systems, 11(10), 550 .

Pintrich, P.R., Smith, D. A. F., Garcia, T., \& McKeachie, W. J. (1991). A manual for the use of the motivated strategies for learning questionnaire (MSLQ). Ann Arbor, MI: The University of Michigan. Retrieved from https://eric.ed.gov/?id=ED338122

Pintrich, P. R., \& DeGroot, E. (1990). Quantitative and qualitative perspectives on student motivational beliefs and self-regulated learning. In Annual meeting of the American Educational Research Association, Boston.

Puzziferro, M. (2008). Online technologies self-efficacy and self-regulated learning as predictors of final grade and satisfaction in college-level online courses. The American Journal of Distance Education, 22(2), 72-89.

Rienties, B., Tempelaar, D., Van den Bossche, P., Gijselaers, W., \& Segers, M. (2009). The role of academic motivation in Computer-Supported Collaborative Learning. Computers in Human Behavior, 25(6), 1195-1206.

Rogers, Y., \& Price, S. (2008). The role of mobile devices in facilitating collaborative inquiry in situ. Research and Practice in Technology Enhanced Learning, 3(3), 209-229.

Schugurensky, D. (2000). The forms of informal learning: Towards a conceptualization of the field. (Unpublished doctoral dissertation). University of Toronto, Toronto.

Sins, P. H., van Joolingen, W. R., Savelsbergh, E. R., \& van Hout-Wolters, B. (2008). Motivation and performance within a collaborative computer-based modeling task: Relations between students' achievement goal orientation, self-efficacy, cognitive processing, and achievement. Contemporary Educational Psychology, 33(1), 58-77. 
Stipek, D. J. (1996). Motivation and instruction. Handbook of Educational Psychology, 85-113.

Suh, S., \& Kim, S. (2013). Study on policy for an entrance quota of cyber universities. Seoul, Korea: Korea Educational Information and Research Service.

Sweller, J., Van Merriënboer, J. J. G., \& Paas, F. (1998). Cognitive architecture and instructional design. Educational Psychology Review, 10, 251-296.

Tindale, R. S., \& Sheffey, S. (2002). Shared information, cognitive load, and group memory. Group Processes \& Intergroup Relations, 5(1), 5-18.

Tsay, M., \& Brady, M. (2012). A case study of cooperative learning and communication pedagogy: Does working in teams make a difference? Journal of the Scholarship of Teaching and Learning, $10(2), 78-89$.

Van Merriënboer, J. J. G., \& Sweller, J. (2010). Cognitive load theory in health professional education: Design principles and strategies. Medical Education, 44(1), 85-93. https://doi.org/10.1111/j.13652923.2009.03498.x

Vansteenkiste, M., Lens, W., \& Deci, E. L. (2006). Intrinsic versus extrinsic goal contents in selfdetermination theory: Another look at the quality of academic motivation. Educational Psychologist, 41(1), 19-31.

Vaughan, N., Nickle, T., Silovs, J., \& Zimmer, J. (2011). Moving to their own beat: Exploring how students use web 2.o technologies to support group work outside of class time. Journal of Interactive Online Learning, 1O(3), 113-127.

Wittenbaum, G. M., \& Stasser, G. (1996). Management of information in small groups. In J. L. Nye \& A. M. Brower (Eds.), What's social about social cognition (pp. 3-28). Thousand Oaks, CA: Sage

Wolters, C. A. (2004). Advancing achievement goal theory: Using goal structures and goal orientations to predict students' motivation, cognition, and achievement. Journal of Educational Psychology, 96(2), 236.

Wosnitza, M., \& Volet, S. (2009). A framework for personal content goals in collaborative learning contexts. Contemporary motivation research: From global to local perspectives, 49-67.

Yuan, L., \& Powell, S. (2013). MOOCs and open education: Implications for higher education. Bolton: University of Bolton, Centre for Educational Technology, Interoperability and Standards \& JISC. Retrieved from http://publications.cetis.ac.uk/2013/667

Zhu, C. (2012). Student satisfaction, performance, and knowledge construction in online collaborative learning. Educational Technology \& Society, 15(1), 127-136. 


\section{Appendix}

\section{OCU Survey June 2016}

1. Age

2. Gender

3. In a class like this, I prefer course material that really challenges me so I can learn new things.

4. In a class like this, I prefer course material that arouses my curiosity, even if it is difficult to learn.

5. The most satisfying thing for me in this course is trying to understand the content as thoroughly as possible.

6. When I have the opportunity in this class, I choose course assignments that I can learn from even if they don't guarantee a good grade.

7. The lecture really enhanced my understanding of the topic.

8. The lecture really enhanced my knowledge and understanding of the of the class subject.

9. The lectured really enhanced my understanding of the concepts associated with the class subject.

10. The lecture really enhanced my understanding of concepts and definitions.

11. How did you interact with people you know at your university who were taking the same class?

- We talked generally about the class ("The class is easy, the class is stressful")

- We talked about the contents of the class

- We had regular study groups 
- We shared notes or materials

- I never interacted with anyone from my university

$\circ \quad$ Other (please fill out)

Athabasca

University

(c) 